\title{
Dedifferentiated Chondrosarcoma of the Larynx: A Case Report and Review of the Literature
}

\author{
Kelsey C Hinther ${ }^{1}$ and Rick Jaggi ${ }^{2 *}$ \\ ${ }^{1}$ College of Medicine, University of Saskatchewan, Canada \\ ${ }^{2}$ Division of Otolaryngology, University of Saskatchewan, Canada
}

Submission: November 01, 2017; Published: March 29, 2018

*Corresponding author: Rick Jaggi, Royal University Hospital, 103 Hospital Drive, Saskatoon, Saskatchewan, Canada

\begin{abstract}
Background: Laryngeal chondrosarcomas are rare, slow-growing, cartilaginous tumors. Dedifferentiated chondrosarcomas, a rare entity of chondrosarcoma, are more aggressive and associated with a more ominous prognosis. Definite diagnosis can be established by incisional biopsy and histopathologic examination. Histopathologic examination reveals a cartilaginous tumor with a malignant spindle cell component. Definitive reatment of dedifferentiated chondrosarcomas of the larynx is total laryngectomy. There have been 14 case reports of laryngeal dedifferentiated chondrosarcoma reported since 1988. The average life expectancy reported is 6 months, and a 5 -year survival rate of $10.5 \%$.

Case presentation: We present a case of dedifferentiated chondrosarcoma arising in the cricoids cartilage of a male patient, who presented with 3-week history of dyspnea, stridor, dysphonia and intermittent aphonia. As a result, he underwent a total laryngectomy, and received adjuvant radiation therapy.

Conclusion: Laryngeal dedifferentiated chondrosarcoma is a rare entity. Symptoms include dyspnea, hoarseness, dysphagia, and a painless neck mass. Due to the aggressiveness of the tumor, it is essential to include it as a differential diagnosis among the other laryngeal tumors.

Keywords: Chondrosarcoma; Dedifferentiated; Larynx; Malignancy

Abbreviations: DC: Dedifferentiated Chondrosarcoma; PL: Partial Laryngectomy; TL: Total Laryngectomy; BND: Bilateral Neck Dissection; TT: Total Thyroidectomy; WE: Wide Excision; ART: Adjuvant Radiotherapy; ARC: Adjuvant Radiochemotherapy; DRMD: Died Of Regional Metastatic Disease; DDMD: Died Of Distant Metastatic Disease; NED: Alive With No Evidence Of Malignancy; AMD: Alive With Metastatic Disease; DOD: Died Of Other Cause
\end{abstract}

\section{Introduction}

Chondrosarcoma (CS) is a slow-growing malignant mesenchymal tumor with cartilaginous differentiation. CS, as a whole, is relatively common [1-4]. These tumors are most commonly located in the pelvis, femur, ribs, humerus, scapula, fibula, sacrum, or sternum; accounting for about $10-20 \%$ of malignant primary bone tumors [1-3,5-8]. Paranasal sinuses, nasal cavity, temporal bone, mandible and larynx were the most common sites of head and neck chondrosarcomas origin [9]. Laryngeal chondrosarcomas are a raretumor, and account for only $<0.2 \%$ of all head and neck malignancies [1,2,4,6,10-12]. Among the subtypes of CS, dedifferentiated CS (DC) is a rare, sinister variant associated with a poor prognosis of an average life-expectancy of 6 months, and a 5-year survival rate of $10.5 \%$.

There have been numerous reports of laryngeal CS, however, there are only 14 reports of laryngeal DC. Here we present a case study of DC of the cricoid cartilage, including the clinical presentation, investigations, and management.

\section{Case Presentation}

A 56-year-old Caucasian male was referred to the ENT clinic with a 3-week history of dyspnea, stridor, dysphonia and intermittent aphonia. Associated symptoms included frequent throat clearing, globus pharyngeus, hoarseness and dysphagia. The patient lost 40 pounds over a 4- month period, and progressively became more fatigued. He quit smoking 15 years ago. Prior to that, he smoked 10 cigarettes daily for 20 years. He denied the use of alcohol or recreational drugs. Past medical history was significant for hypertension, prediabetes, sleep apnea, COPD and GERD. The senior author felt the later three diagnoses were secondary to the laryngeal chondrosarcoma as they resolved post-laryngectomy. His head and neck examinations were normal.

Flexible endoscopic laryngoscopy revealed left vocal cord immobility, with the vocal cords in themedian position, and what 


\section{International Journal of Cell Science \& Molecular Biology}

appeared endoscopically to be subglottic stenosis. He underwent a head, neck and chest CT scan to rule out any sinister lesions along the course of the recurrent laryngeal nerve. Imaging revealed a 4 x $4 \mathrm{~cm}$ left cricoid chondrosarcoma (Figure 1).

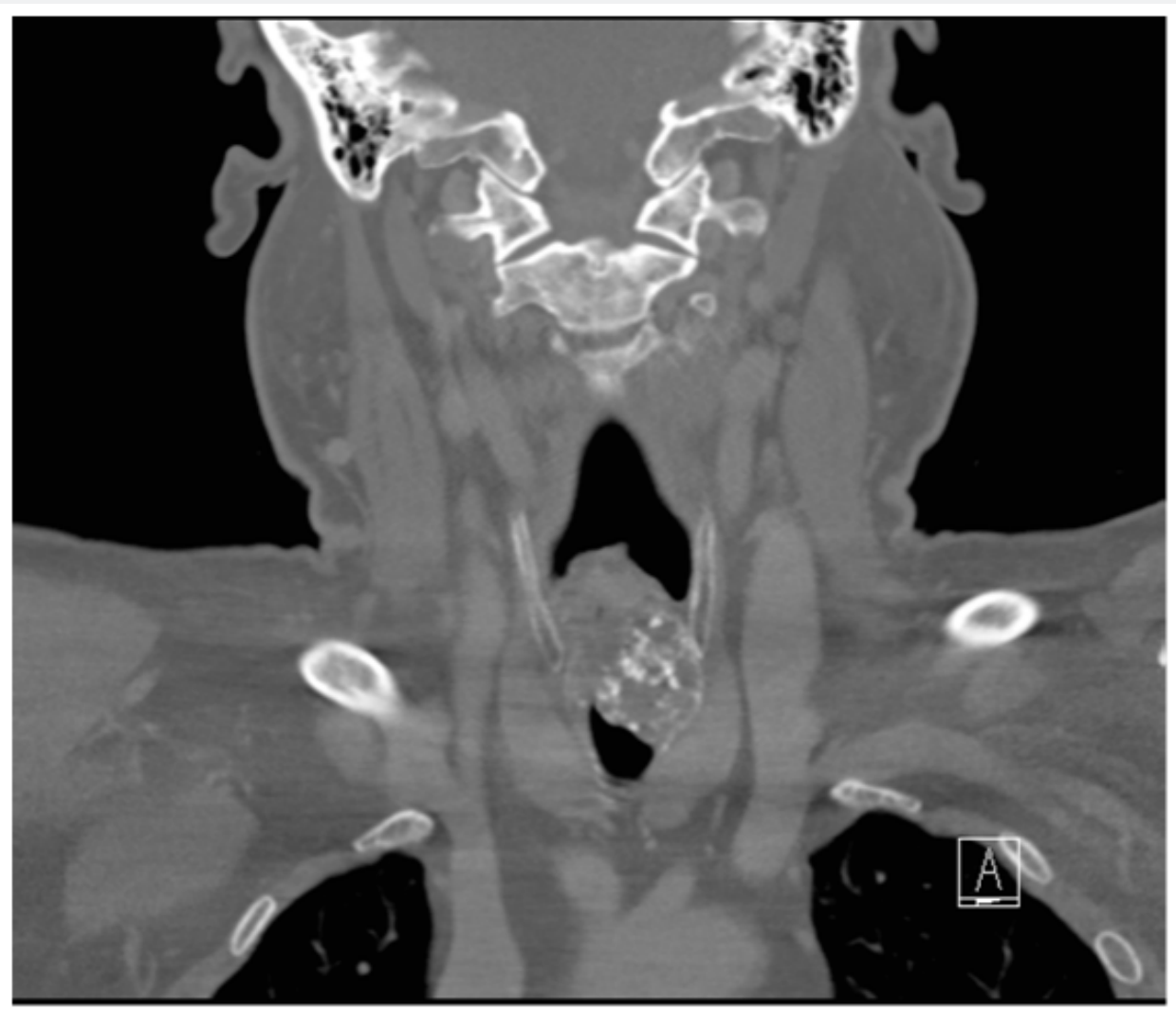

Figure 1: Coronal computed tomography scan of the larynx revealing a calcified tumor arising from the from the cricoids cartilage.

The CT scan revealed a chondrosarcoma, a poorly defined mixed soft tissue and calcified mass measuring $3.0 \times 2.0 \mathrm{~cm}$ in the axial dimension, and $3.5 \mathrm{~cm}$ in the superior-inferior dimension, centered on theposterior left lateral aspect of the cricoid cartilage. The mass extended superiorly to the false vocal cords, and inferiorly, just below the true vocal cords. Just below the true vocal cords, there was significant narrowing of the airway. The lumen measured $2.5 \mathrm{~cm}$ in the anterior-posterior dimension, and only $4 \mathrm{~mm}$ in the transverse dimension. Destruction of most of the cricoid cartilage was identified. There was no evidence of cervical lymphadenopathy. The lungs were clear and there was no mediastinal lymphadenopathy. Diffuse fatty filtration of the liver was present with a poorly defined $1.2 \mathrm{~cm}$ hypodense mass in the right lobe.

Shortly after the CT scan was done, the patient was admitted to hospital with severe respiratory distress and complete aphasia, he subsequently underwent a microlaryngoscopy, biopsy and tracheostomy. The patient's dyspnea resolved following the procedure. Due to the histological findings concluding laryngeal chondrosarcoma with a non-functional larynx, he underwent a narrow field total laryngectomy, cricopharyngeal myotomy, and tracheoesophageal puncture with placement of voice prosthesis. Postoperatively, he recovered well and his speech was $100 \%$ intelligible.

Within the total laryngectomy specimen, a firm tumor located in the left larynx was identified (Figure 2).The tumor extended proximally from the false vocal cords, and distally, into the subglottis. The tumor invaded both, the thyroid and cricoid cartilages. The resection superior and inferior margins were negative. The anterior margins were $4 \mathrm{~mm}$, and the posterolateral and posterior margins appeared to potentially involve the tumor. The histological findings, shown in Figure 3, revealed areas of well-differentiated cartilaginous regionsjuxtaposed with poorlydifferentiated spindle cell sarcoma, arising from the cricoid cartilage. This finding was consistent with dedifferentiated chondrosarcoma. 


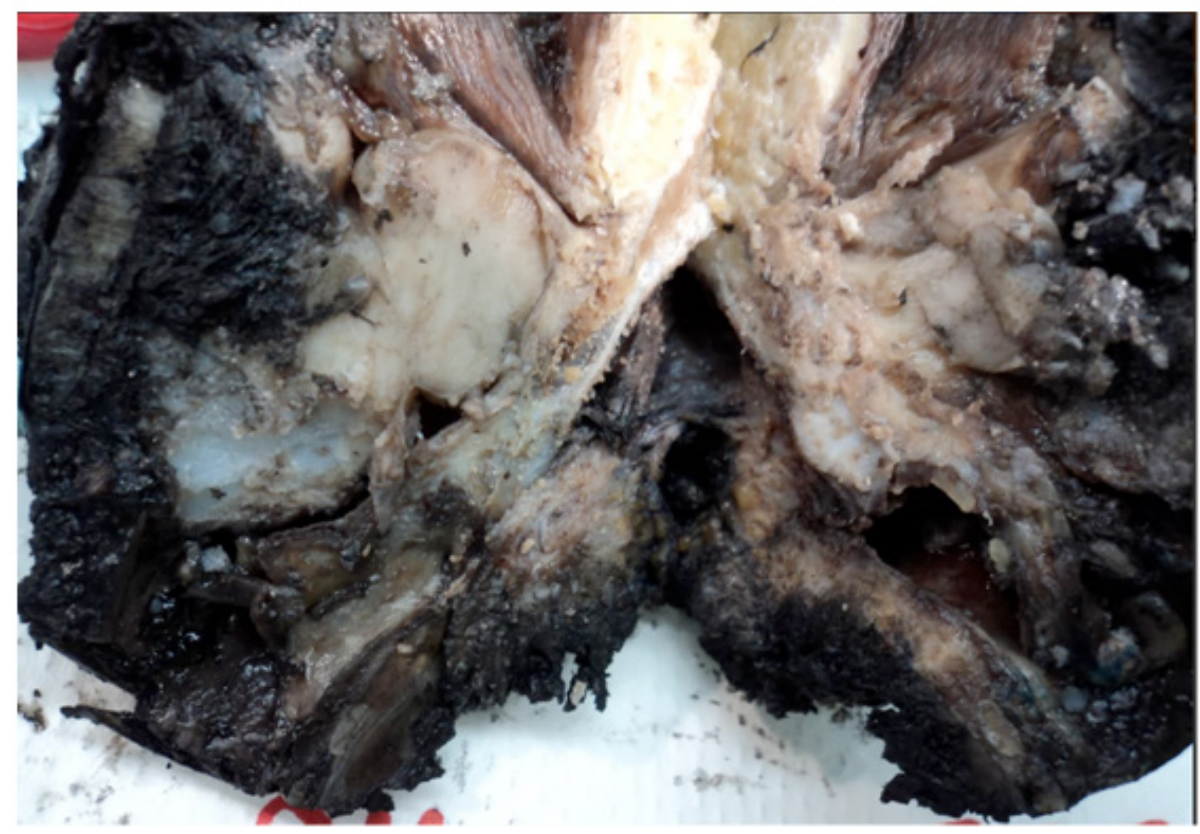

Figure 2: The total laryngectomy specimen revealing a firm tumor located in the left larynx.

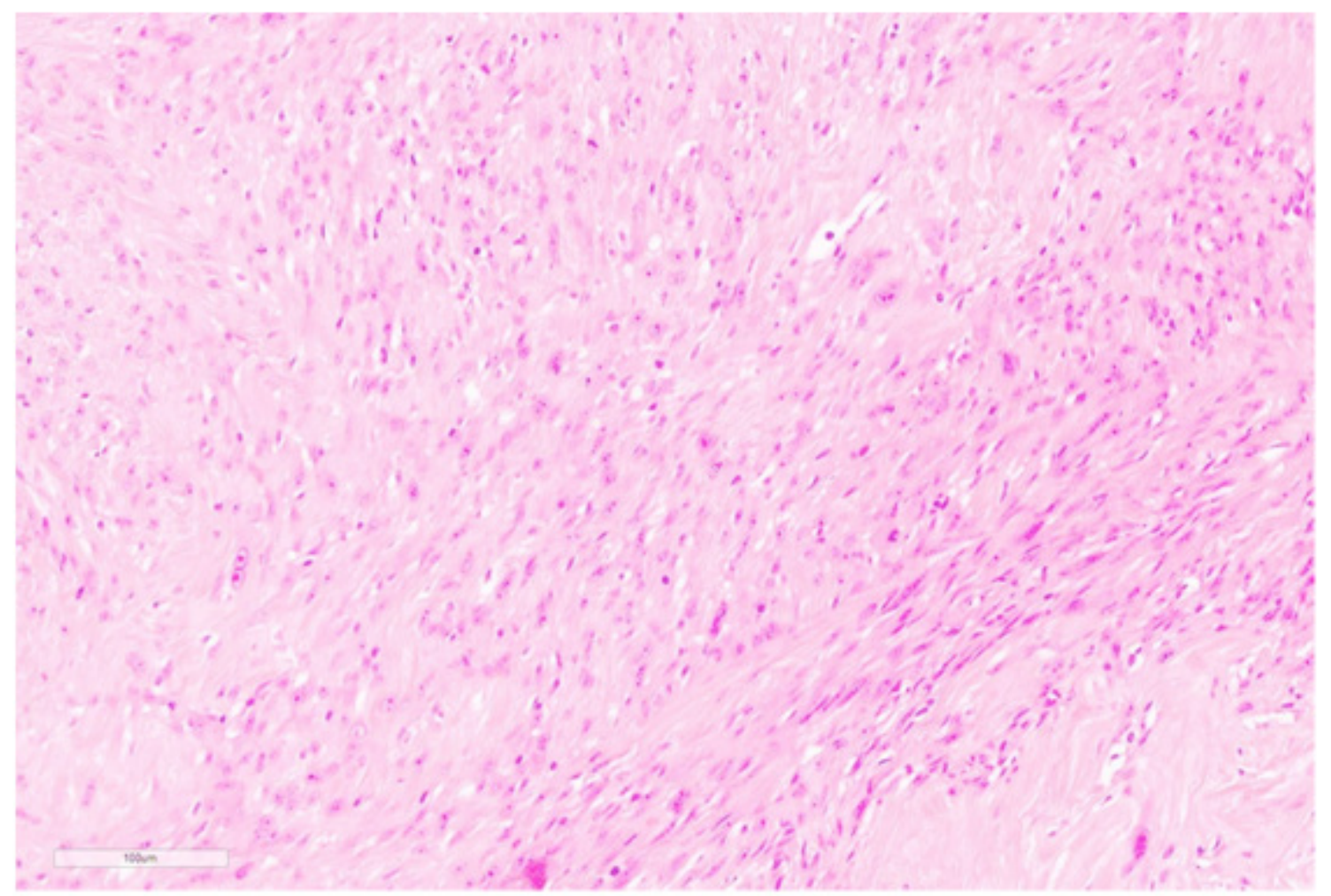

Figure 3: The histological slide revealing areas of well-differentiated cartilaginous regions juxtaposed with poorly- differentiated spindle cell sarcoma, arising from the cricoid cartilage. 
A PET scan was completed to rule out persistent or recurrent disease in the pharyngeal region. There was no evidence of hypermetabolic adenopathy, pulmonary nodules, or hypermetabolic activity in the neckintraabdominal or pelvic organs. However, focal hypermetabolism was present in the superior aspect of thesternal body, either associated with a fracture or alternatively, a metastatic lesion. Further, imaging with theMRI revealed a healing non-displaced sternal fracture. There was no evidence of metastatic bone disease.

Radiation treatment to the laryngeal bed is recommended for intermediate and poorly dedifferentiated chondrosarcoma due to an ominous prognosis, high risk of local recurrence and distant metastases. Furthermore, in the patient's case, radiation is recommended due to the close margins revealed in the total laryngectomy specimen. In this case, a total dose of 66Gy in 33 fractions of external beam radiation therapy was completed. The patient will continue to receive ongoing assessment, including 3-monthly appointments for the first two years, 4-monthly appointments in the third year, and following with 6-monthly appointments. Moreover, a chest x-ray twice annually, and further CT scans as indicated.

\section{Discussion}

Laryngeal chondrosarcoma is the most common nonepithelial laryngeal neoplasm [7,13-15]. The incidence of chondrosarcoma increases with age, with the majority of cases arising in the sixth and seventh decade of life $[3,6,7,10,11,13,15$ 17]. Unlike other head and neck chondrosarcomas, laryngeal chondrosarcomas are relatively slow growing, low- grade neoplasms. Local excision is curative in most cases. Laryngeal chondrosarcomas typically originate from hyaline cartilage. Approximately $75 \%$ of cases arise from the posterior lamina of the cricoid cartilage $[3,4,6-8,10-12,15,16,18-22]$. The rest originate from the thyroid, arytenoid, epiglottis and accessory cartilages $[3,6,12,15,16,18,20-22]$. The exact pathogenesis of laryngeal chondrosarcomas remains unknown [2,3,6,7,11,15$17,19]$.

Dedifferentiated chondrosarcomas of the larynx are extremely rare. Currently there are 14 cases reported in the literature, including this report (Table 1 \& Figure 4). The term dedifferentiated chondrosarcoma was first termed by Dahlin and Beabout in 1971 [9,18,22,23]. DC, a rare entity of chondrosarcoma, has an estimated incidence of $8-14 \%$ of all laryngeal chondrosarcomas [9]. DC are aggressive and present with a poor prognosis $[13,20]$. DC commonly arise among the older adult population, with a male predilection [10]. Compared to the cases of DC reported in the literature, the clinical presentation, investigations and treatments were all similar.

Diagnosis of DC includes a combination of pertinent information on history, physical examination, imaging, and histological and immunocytochemical analyses. Definite diagnosis can be established by incisional biopsy and histopathological examination. The utility of FNA has only been described in 1 DC case. FNA can be performed in an outpatient setting with minimal complications; it is also efficient and costeffective. Despite the advantages, the senior author does not recommend FNA in the case of chondrosarcoma; there is a risk of collecting non- representative tissue, it is difficult distinguishing benign and malignant tumors, and grading and classifying lesions [9].

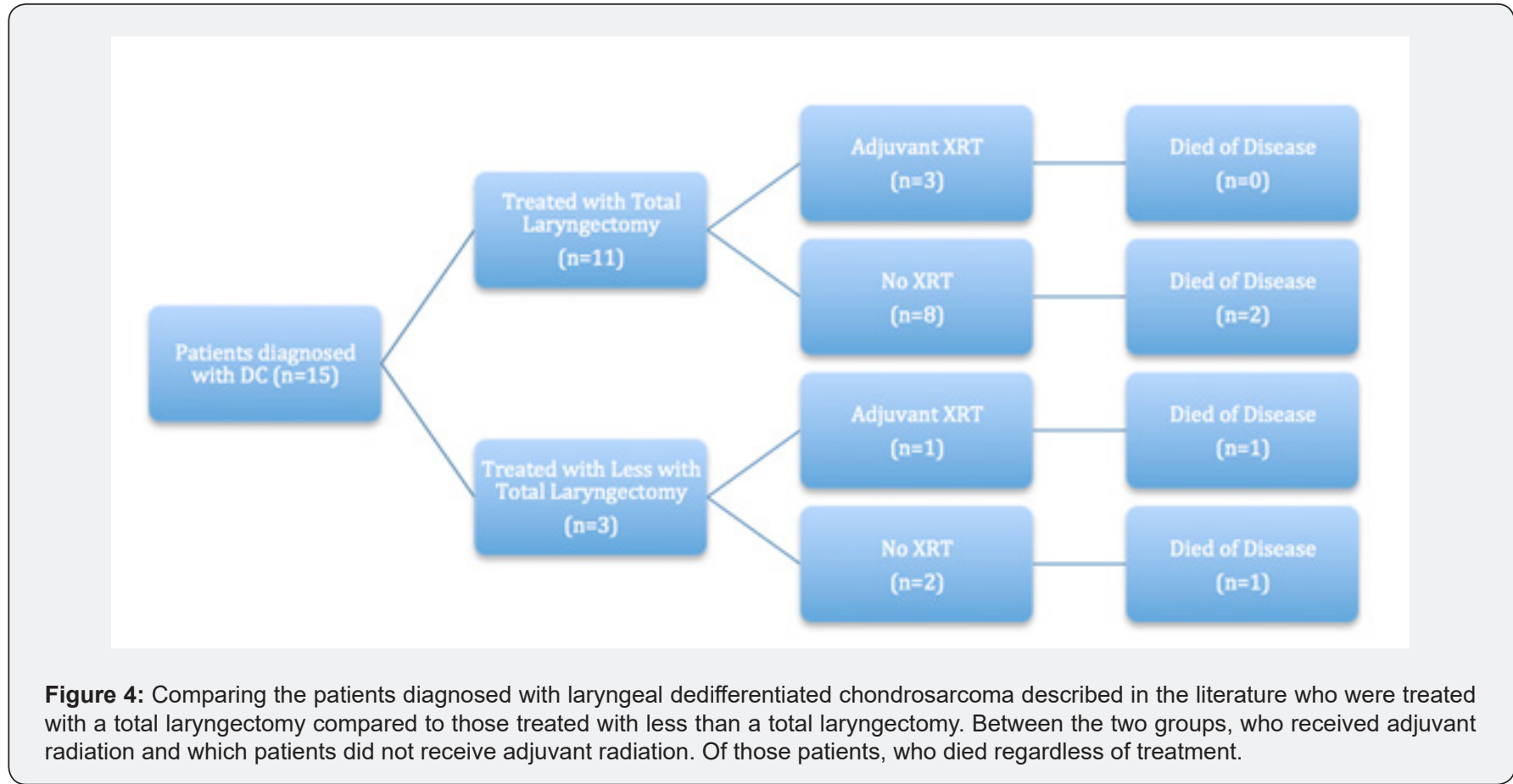


International Journal of Cell Science \& Molecular Biology

Table1: Dedifferentiated chondrosarcoma of the larynx: Data from published case studies.

\begin{tabular}{|c|c|c|c|c|c|c|c|}
\hline $\begin{array}{l}\text { Case } \\
\text { No. }\end{array}$ & Authors & Date & Age & Sex & Diagnosis & Treatment & Outcome \\
\hline 1 & $\begin{array}{l}\text { Bleiweiss IJ, } \\
\text { Kaneko M }\end{array}$ & 1988 & 58 & M & DC & $\mathrm{TL}$ & NED (5y) \\
\hline 2 & $\begin{array}{l}\text { Brandwein M, } \\
\text { Moore S, Som } \\
\text { P, Biller H }\end{array}$ & 1992 & 69 & M & DC & $\begin{array}{l}\text { PL 1974; Laser 1987; tracheal } \\
\text { resection and RT 1991 ART }\end{array}$ & $\begin{array}{l}\text { Stromal } \\
\text { recurrence1991 } \\
\text { LN,1992 DOD }\end{array}$ \\
\hline 3 & $\begin{array}{l}\text { Brandwein M, } \\
\text { Moore S, Som } \\
\text { P, Biller H }\end{array}$ & 1992 & 73 & M & DC & $\mathrm{TL}$ & NED (5y) \\
\hline 4 & $\begin{array}{l}\text { Nakayama M, } \\
\text { Brandenburg } \\
\text { JH, Hafez GR }\end{array}$ & 1993 & 58 & $\mathrm{~F}$ & DC & TL, 4 recurrences excised & DOD \\
\hline 5 & $\begin{array}{l}\text { Nakayama M, } \\
\text { Hafez GR }\end{array}$ & 1993 & 62 & M & DC & WE, TL & AMD \\
\hline 6 & $\begin{array}{l}\text { Faquin WC, } \\
\text { Pilch BZ, Keel } \\
\text { SB, et al. }\end{array}$ & 1999 & 74 & M & DC & TL, RT & $\mathrm{N} / \mathrm{A}$ \\
\hline 7 & $\begin{array}{l}\text { Sakai O, } \\
\text { Curtin HD, } \\
\text { Faquin WC, } \\
\text { et al. }\end{array}$ & 2000 & 74 & M & DC & $\mathrm{TL}$ & $\mathrm{N} / \mathrm{A}$ \\
\hline 8 & $\begin{array}{c}\text { Garcia RE, } \\
\text { Gannon FH, } \\
\text { Thompson } \\
\text { LDR }\end{array}$ & 2002 & 67 & M & DC & WE & DOD (11.3y) \\
\hline 9 & $\begin{array}{c}\text { Garcia RE, } \\
\text { Gannon FH, } \\
\text { Thompson } \\
\text { LDR }\end{array}$ & 2002 & 41 & M & DC & $\mathrm{TL}$ & NED (7.6y) \\
\hline 10 & $\begin{array}{l}\text { Casiraghi 0, } \\
\text { Martinez- } \\
\text { Madrigal } \\
\text { F, Pineda- } \\
\text { Daboin K, } \\
\text { et al. }\end{array}$ & 2004 & 61 & M & DC & $\mathrm{TL}, \mathrm{ND}$ & NED (5yr) \\
\hline 11 & $\begin{array}{l}\text { Casiraghi O, } \\
\text { Martinez- } \\
\text { Madrigal } \\
\text { F, Pineda- } \\
\text { Daboin K, } \\
\text { et al. }\end{array}$ & 2004 & 58 & M & DC & $\mathrm{TL}$ & DOD (2y) \\
\hline 12 & $\begin{array}{l}\text { Rinaggio J } \\
\text { Duffey D, } \\
\text { McGuff HS }\end{array}$ & 2004 & 60 & M & DC & $\begin{array}{l}\text { Debulking with CO2laser, TL } \\
\text { with BND,ART }\end{array}$ & $\begin{array}{l}\text { Right } \\
\text { lungmetastatic } \\
\text { disease }\end{array}$ \\
\hline 13 & $\begin{array}{c}\text { Purohit BS, } \\
\text { Dulguerov P, } \\
\text { Burkhardt K, } \\
\text { et al. }\end{array}$ & 2014 & 69 & M & DC & $\begin{array}{c}\text { TL, } \\
\text { TT,noncircumferentialresection } \\
\text { of } 5 \mathrm{~m} \text { ofupper esophagus,ARC }\end{array}$ & NED(3y) \\
\hline 14 & $\begin{array}{l}\text { Fidai SS, } \\
\text { Ginat DT, } \\
\text { Langerman A, } \\
\text { et al. }\end{array}$ & 2015 & 55 & M & DC & PL & NED(8mos) \\
\hline
\end{tabular}




\section{Symptomology}

Presenting symptoms vary depending on the anatomic location of the tumor. In the literature, common symptoms reported include hoarseness due to narrowing of the glottis and compression of the inferior laryngeal nerves, dyspnea and airway obstruction as a result of endolaryngeal and subglottic growth, dysphagia due to extralaryngeal growth of the tumor originating in the posterior cricoid, and a painless neck mass from tumor the involving the thyroid cartilage $[7,10,11,12,13,18]$. Rapid progression of symptoms over days or weeks should raise the suspicion of the lesion may be more aggressive than the standard laryngeal well-differentiated chondrosarcoma.

\section{Histopathology}

Histopathologic grading of chondrosarcomas is based on the criteria first described by Lichtenstein and Jaffe in 1943. The grading system stratifies the tumor into three different grades, from low to high grade according to cellularity, nuclear size and pleomorphism, necrosis and mitotic activity. This classification system assists with delineating the tumor's aggressiveness and prognosis, and subsequent treatment. Higher-grade neoplasms are associated with higher aggressiveness and a poorer prognosis $[6,7,15,16,20,23]$. Histological analysis remains the goldstandard for diagnostic purposes $[3,6,10]$. The histopathologic hallmark of DC concluded in case studies is the presence of an abrupt transition between low grade cartilaginous component juxtaposed on a high- grade, noncartilaginous, spindle cell sarcoma with pleomorphism, vesicular nuclei, giant cells, and numerous mitoses[4,5,9,10,13,18,23]. The cartilaginous portion of the tumor can contain some cells of DC, and thus the entire tumor must be examined.

Morphologically, the features of DC are similar to undifferentiated sarcoma, osteosarcoma, rhabdomyosarcoma, leiomyosarcoma or angiosarcoma $[6,10,13,18]$.

\section{Immunohistochemistry}

Immunochemical findings were not described in this case, however other studies concluded that the malignant spindle cell component of DC is strongly positive for vimentin, focally positive for alpha-1-anti-chymotrypsin, and negative for cytokeratins, S-100 protein, desmin and muscle-specific act in $[9,13,18,22]$.

\section{Imaging}

According to the literature, CT scan is the imaging modality of choice. Stippled to coarse calcifications within the tumor is a patho gnomonic finding for laryngeal chondrosarcoma. This feature can be seen in tumors of any grade. Thus, imaging alone is not sufficient to make the diagnosis of dedifferentiated chondrosarcoma $[2,4,6,7,10,12,15,16,18]$. This finding cannot be appreciated on MRI. MRI is a useful complementary image modality for determining the extent of the tumor, as well as treatment planning and prognosis.
Destructive invasion of the cartilage, bone or soft tissue may suggest a high-grade tumor [10]. One study outlined the feasibility of multimodality imaging with PET and MRI, including DW-MRI. PET and MRI provide additional information regarding the hyper metabolic, aggressive dedifferentiated component, and the hyper metabolic, low-grade component [4].

\section{Treatment}

The standard treatment for laryngeal cartilaginous tumors is surgical excision, with preservation of the function of the larynx, if feasible $[2-4,8,11,14,16,17,20]$. However, due to the aggressiveness of the DC, the definitive treatment remains total laryngectomy $[4,21]$. Nonetheless, partial laryngectomy has been reported in a few cases. It is also recommended that patients with laryngeal DC receive adjuvant radiotherapy [2]. Although in this case, the patient received adjuvant radiation therapy, there have been previously reported cases in the literature in which the patient did not receive adjuvant therapy following surgical excision $[5,17]$. The role of radiation therapy remains undetermined [4]. Follow-up reveals a variable clinical course among the reported cases. Some patients remain disease free, whilst others develop metastatic disease $[10,20]$.

\section{Prognosis}

Compared to low-grade chondrosarcomas, DC has been shown to have a poorer prognosis with a high rate of recurrence and a predisposition of distant metastases $[3,4,8,13,18,23]$. The average life-expectancy reported is 6 months, and a 5-year survival rate of $10.5 \%$. Approximately $70 \%$ of patients develop pulmonarymetastatic disease some time during their disease course $[18,23]$.

\section{Conclusion}

DC is a rare entity in the larynx. DC typically arises in the cricoid cartilage, presenting with rapidly Progressive dyspnea, hoarseness, dysphagia, and a painless neck mass. Due to the aggressiveness of thetumor, it is essential to include DC as a differential diagnosis among the other laryngeal tumors $[24,25]$.

\section{Acknowledgement}

Thank you to Dr. Brent Wilde for providing photographs of the histology slide and of the gross specimen of the dedifferentiated chondrosarcoma of the larynx.

\section{References}

1. Miyamaru S, Haba Laryngeal K (2014) Chondrosarcoma diagnosed by core-needle biopsy. Am J Otolaryngol 35(4): 535-537.

2. Coca-Pelaz A, Rodrigo JP, Triantafyllou A (2014) Chondrosarcomas of the head and neck. Eur Arch Otorhinolaryngol 271: 2601-2609.

3. Policarpo M, Taranto F, Aina E (2008) Chondrosarcoma of the larynx: a case report. Acta Otorhinolaryngol Ital 28(1): 38-41.

4. Purohit BS, Dulguerov P, Burkhardt K (2013) Dedifferentiated laryngeal chondrosarcoma: Combined morphologic and functional 
imaging with positron-emission tomography/magnetic resonance imaging. Laryngoscope 124(7): E274-E277.

5. Roth R, Das BK, Baisakh M (2014) Dedifferentiated chondrosarcoma of temporomandibular joint: Atypical features of a rare case. J Clin Diagn Res 8(9): 9-11.

6. Oliveira JF, Branquinho FA, Monteiro AR (2014) Laryngeal chondrosarcoma- Ten years of experience. Braz J Otorhinolaryngol 80(4): 354-358.

7. Buda I, Hod R, Feinmesser R (2012) Chondrosarcoma of the larynx. IMAJ 14: 681-684.

8. Vincentiis M, Greco A, Fusconi M (2011) Total cricoidectomy in the treatment of laryngeal chondrosarcomas. Laryngoscope 121(11): 2375-2380.

9. Faquin WC, Pilch BZ, Keel SB (2000) Fine- needle aspiration of dedifferentiated chondrosarcoma of the larynx. Diagn Cytopathol 22(5): 288-292.

10. Fidai SS, Ginat DT, Langerman AJ (2015) Dedifferentiated chondrosarcoma of the larynx. Head and Neck Pathol 1-4.

11. Wang Q Chen H, Zhou S (2015) Chondrosarcoma of the larynx: report of two cases and review of the literature. Int J Clin Exp Pathol 8(2): 2068-2073.

12. Thompson LDR, Gannon FH (2002) Chondrosarcoma of the larynx: A clinicopathologic study of 111 cases with a review of the literature. Am J Surg Pathol 26(7): 836-851.

13. Rinaggio J (2004) Dedifferentiated chondrosarcoma of the larynx. Oral Surg Oral Med Oral Pathol Oral Radiol Endod 97(3): 369-375.

14. Dailiana T, Nomikos P, Kapranos N (2002) Chondrosarcoma of the larynx: treatment with radiotherapy. Skeletal Radiol 31: 547-549.

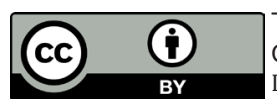

This work is licensed under Creative

Commons Attribution 4.0 Licens

DOI: 10.19080/IJCSMB.2018.04.555631
15. Stefano R, Paolo B, Dimitrios P (2015) Chondrosarcoma of the laryngeal thyroid cartilage. J Craniofac Surg 26(6): 478-479.

16. Sauter A, Bersch C, Lambert KL (2007) Chondrosarcoma of the larynx and review of the literature. Anticancer Res 27: 2925-2930.

17. Casiraghi O, Martinez-Madrigal F, Pineda-Daboin K (2004) Chondroid tumors of the larynx: A clinicopathologic study of 19 cases, including two dedifferentiated chondrosarcomas. Ann Diagn Pathol 8(4):189197.

18. Sakai O, Curtin HD, Faquin WC (2000) Dedifferentiated chondrosarcoma of the larynx. AJNR 21: 584-586.

19. Dubal PM, Svider PF, Kanumuri VV (2014) Laryngeal chondrosarcoma: A population-based analysis. Laryngoscope 124(8): 1877-1881.

20. Garcia RE, Gannon FH, Thompson LDR (2002) Dedifferentiated chondrosarcoma of the larynx: a report of two cases and review of the literature. Laryngoscope 112(6): 1015-1018.

21. Nakano Y, Asakura K, Himi T (1999) Chondrosarcoma of the larynx: a case successfully reconstructed after total cricoidectomy. Auris Nasus Larynx 26(2): 207-211.

22. Brandwein M, Moore S, Som P, Biller H (1992) Laryngeal chondrosarcomas: a clinicopathologic study of 11cases, including two "dedifferentiated" chondrosarcomas. Laryngoscope 102(8): 858-867.

23. Nakayama M, Brandenburg JH, Hafez GR (1993) Dedifferentiated chondrosarcoma of the larynx with regional and distant metastases. Ann Otol Rhinol Laryngol 102(10): 785-791.

24. Bleiweiss IJ, Kaneko M (1988) Chondrosarcoma of the larynx with additional malignant mesenchymal component (dedifferentiated chondrosarcoma). Am J Surg Pathol 12(4): 314-320.

25. Finn DG, Goepfert H, Batsakis JG (1984) Chondrosarcoma of the head and neck. Laryngoscope 94:1539-1544.

\section{Your next submission with Juniper Publishers will reach you the below assets}

- Quality Editorial service

- Swift Peer Review

- Reprints availability

- E-prints Service

- Manuscript Podcast for convenient understanding

- Global attainment for your research

- Manuscript accessibility in different formats ( Pdf, E-pub, Full Text, Audio)

- Unceasing customer service

Track the below URL for one-step submission https://juniperpublishers.com/online-submission.php 